\title{
AÇÃO EDUCATIVA PARA A PADRONIZAÇÃO NO MANEJO DO CATETER DE HICKMAN $^{\circledR}$
}

\author{
Mitzy Tannia Reichembach Danski ${ }^{1}$, Sandra Regina da Silva², Letícia Pontes ${ }^{1}$, Edivane Pedrolo $^{3}$
}

RESUMO: Objetivo: habilitar a equipe de Enfermagem de um serviço de transplante de células-tronco hematopoiéticas no manejo do cateter de Hickman ${ }^{\circledR}$. Método: pesquisa descritiva e quantitativa. A coleta de dados ocorreu entre janeiro e março de 2017, em um hospital público do Sul do Brasil, por meio de questionários que foram analisados mediante estatística descritiva. Resultados: habilitaram-se 44 participantes. Das questões abordadas, tiveram melhor resultado após as orientações: definição de cateter venoso central de curta permanência (79,55\% para 93,18\%de acertos); material e posição do cateter (75\% para 88,64\%); características do cateter (54,55\% para 65,91\%); procedimentos imediatos à inserção do cateter (2,27\% para 18,18\%); lavagem, pressão positiva e refluxo induzido pela seringa $(72,73 \%$ para $97,73 \%)$; bloqueio do cateter (84,09\% para 97,73\%); volume do priming(22,73\%para 54,55\%). Conclusão: o processo educativo desenvolvido possibilitou a instrumentalização dos profissionais para um conhecimento mais homogêneo no manejo do cateter de Hickman ${ }^{\circledR}$.

DESCRITORES: Enfermagem baseada em evidências; Cateteres venosos centrais; Transplante de células-tronco hematopoiéticas; Capacitação em serviço.

\section{EDUCATIONAL ACTION FOR STANDARDIZATION IN THE MANAGEMENT OF HICKMAN ${ }^{\circledR}$ CATHETERS}

\begin{abstract}
Objective: to enable the nursing team of a hematopoietic stem cell transplantation service to manage Hickman ${ }^{\circledR}$ catheters. Method: descriptive and quantitative research. Data collection took place between January and March 2017, in a public hospital in the South of Brazil, using questionnaires that were analyzed through descriptive statistics. Results: Forty-four participants were enrolled. Of the issues addressed, the ones with better results after the guidelines were: definition of a short-term central venous catheter (79.55\% for 93.18\% of correct answers); material and position of the catheter (75\% to $88.64 \%)$; characteristics of the catheter $(54.55 \%$ to $65.91 \%)$; immediate procedures after catheter insertion (2.27\% to $18.18 \%)$; flushing, positive pressure and syringe-induced reflux $(72.73 \%$ to $97.73 \%)$; catheter lock ( $84.09 \%$ to $97.73 \%)$; and priming volume (22.73\% to $54.55 \%$ ). Conclusion: the educational process developed allowed the instrumentalization of professionals to a more homogenous knowledge in the management of Hickman ${ }^{\circledR}$ catheters.
\end{abstract}

DESCRIPTORS: Evidence-based nursing; Central venous catheters; Hematopoietic stem cells transplantation; In-service training.

\section{ACCIÓN EDUCATIVA PARA ESTANDARIZAR EL MANEJO DEL CATÉTER DE HICKMAN ${ }^{\circledR}$}

RESUMEN: Objetivo: Capacitar al equipo de Enfermería de un servicio de trasplante de células madre hematopoyéticas en el manejo del catéter de Hickman ${ }^{\circledR}$. Método: Investigación descriptiva, cuantitativa. Datos recolectados entre enero y marzo de 2017 en hospital público delo Sur de Brasil, mediante cuestionarios, que fueron analizados por estadística descriptiva. Resultados: Recibieron capacitación los 44 participantes. Las cuestiones abordadas obtuvieron mejores resultados después de las indicaciones: definición de catéter venoso de corta permanencia (79,55\% al 93,18\% de aciertos); material y posición del catéter (75\% al 88,64\%); características del catéter (2,27\% al 18,18\%); higiene, presión positiva y reflujo inducido por jeringa (72,73\% al 97,73\%); bloqueo del catéter (84,09\% al 97,73\%) volumen del priming (22,73\% al 54,55\%). Conclusión: El proceso educativo desarrollado permitió el desarrollo por parte de los profesionales de un conocimiento más homogéneo en el manejo del catéter de Hickman ${ }^{\circledR}$.

DESCRIPTORES: Enfermería Basada en la Evidencia; Catéteres Venosos Centrales; Trasplante de Células Madre Hematopoyéticas; Capacitación en Servicio.

\footnotetext{
${ }^{1}$ Enfermeira. Doutora em Enfermagem. Docente do Departamento de Enfermagem e do Programa de Pós-Graduação em Enfermagem da Universidade Federal do Paraná. Curitiba, PR, Brasil.

${ }^{2}$ Enfermeira. Mestranda do Programa de Pós-Graduação em Enfermagem da Universidade Federal do Paraná. Curitiba, PR, Brasil.

${ }^{3}$ Enfermeira. Doutoranda do Programa de Pós-Graduação em Enfermagem da Universidade Federal do Paraná. Curitiba, PR, Brasil.
} 


\section{INTRODUÇÃO}

O transplante de células-tronco hematopoiéticas (TCTH) é uma modalidade terapêutica utilizada para doenças hematológicas malignas e não malignas que intenta a permuta da medula óssea deficiente. Esse tratamento traduz-se na infusão de células-tronco hematopoiéticas (CTH), pela via endovenosa, que propicia a reconstituição dos sistemas hematopoiético e imunológico do receptor. Essa permuta pode ser autóloga, em que as células derivam do próprio paciente ou alogênica, quando o doador e o receptor são pessoas diferentes geneticamente, mas com algum grau de compatibilidade dos antígenos leucocitários humanos, podendo ser consanguíneos, ou não(1).

Após o internamento, na fase pré-transplante, o receptor é submetido à implantação de um cateter vascular que deve permanecer permeável durante todo o regime de tratamento, o que requer uma equipe de Enfermagem especializada e habilitada para tal. Isso é fator intrínseco para o sucesso do TCTH ${ }^{(2)}$.

O TCTH é uma terapêutica que exige infusão parenteral intensa para hidratação, infusão de medicamentos, hemocomponentes e células-tronco hematopoiéticas, além deacesso para coletas de sangue para exames diários, o que determina a utilização de um cateter venoso central de longa permanência (CVCLP) semi-implantado (SI) ou tunelizado para assegurar o tratamento parenteral adequado $^{(3)}$.

O cateter de Hickman ${ }^{\circledR}$ é um CVCLP-SI ou tunelizado, não valvulado, produzido com silicone radiopaco, hemocompatível e biocompatível ${ }^{(4)}$. Inserido em ambiente cirúrgico sob anestesia geral ou sedação ${ }^{(5)}$, pode permanecer por um a dois $\operatorname{anos}^{(3)}$. Denomina-se semi-implantável ou tunelizado por sua inserção ocorrer em veia central por um túnel subcutâneo, confeccionado pelo cirurgião, que tem como sítios preferenciais de inserção a veia subclávia ou jugular interna ${ }^{(6)}$. Nesses casos, o óstio de inserção do cateter localiza-se na região torácica anterior, abaixo da linha hemiclavicular, mantendo uma parte do cateter exposta pela qual a terapia intravenosa é realizada ${ }^{(7)}$.

Apesar de amplamente utilizados, os Cateteres Venosos Centrais (CVC) estão sujeitos a diversas complicações incluindo a oclusão. Ela é responsável por 14 a 36\% das complicações relacionadas ao CVCLP, no período de um a dois anos da sua colocação(8) e caracteriza-se como uma das principais complicações relacionadas ao CVCLP-SI de Hickman ${ }^{\circledR(9-10)}$ exigindo, muitas vezes, a sua retirada e expondo o paciente a novo procedimento cirúrgico.

O manejo apropriado desse dispositivo vascular é decisivo para garantir a sua permeabilidade evitando, dentre outras intercorrências, a oclusão ${ }^{(3,11)}$. A oclusão do cateter de Hickman ${ }^{\circledR}$ ou outro CVC é a impossibilidade de infundir solução e/ou aspirar sangue do lúmen do cateter ${ }^{(12)}$.Para a garantia da funcionalidade desse dispositivo, tão importante quanto a solução escolhida para a manutenção da permeabilidade intraluminal é a padronização das ações de manejo desse dispositivo,comoa técnica correta de lavagem e bloqueio.

Para a padronização do manuseio do CVCLP-SI de Hickman ${ }^{\circledR}$ quanto à permeabilidade, considerouse oconceito de educação permanente, que presume a aprendizagem no trabalho. Dessa forma, a partir das dificuldades reais, respeitando o conhecimento e experiência prévia dos envolvidos no processo educativo, busca-se a modificação das práticas, a apropriação do saber técnico-científico e a organização do trabalho. A educação em serviço é relevante ferramenta na efetivaçãode novas e melhores práticas ${ }^{(13-15)}$.

Apadronização de cuidados com o CVCLP-SI de Hickman ${ }^{\circledR}$ consistiu na primeira etapa para o desenvolvimento de um ensaio clínico randomizado triplo cego que teve como objetivo avaliar a efetividade de duas soluções de bloqueio na prevenção de oclusão do CVCLP-SI de Hickman ${ }^{\circledR}$ e se deu pela necessidade de reduzir viés na pesquisa. Objetivou-se avaliar a atividade educativa desenvolvida para habilitar a equipe de Enfermagem de um serviço de TCTH na padronização do manejo do cateter de Hickman ${ }^{\circledR}$ para a prevenção de oclusão. 


\section{METODOLOGIA}

Pesquisa descritiva, de abordagem quantitativa, realizada como etapa inicial para o desenvolvimento de um ensaio clínico randomizado triplo cego. Esta etapa, especificamente, foi caracterizada como um estudo de avaliação do conhecimento dos profissionais por meio de um mesmo questionário aplicado imediatamente antes e logo após a finalização da ação educativa.

A ação educativa foi realizada para padronizar o manejo do cateter de Hickman ${ }^{\circledR}$ a fim de reduzir possíveis vieses de procedimentos para a coleta de dados. Participaram 44 profissionais de Enfermagem entre enfermeiros, técnicos e auxiliares de Enfermagem de um serviço referência para o TCTH localizado na cidade de Curitiba, Estado do Paraná. A coleta de dados ocorreu entre os meses de janeiro a março de 2017.

Importante destacar que, de acordo com a Lei do Exercício profissional, as atividades de alta complexidade só podem ser exercidas por enfermeiros e os profissionais de Enfermagem manipulam o cateter de Hickman ${ }^{\circledast}$ de acordo com sua competência técnica legal.

Todos os participantes preencheram um cadastro com informações profissionais e acadêmicas. Como critério de inclusão, considerou-se: ser profissional de Enfermagem lotado no serviço de TCTH - unidade de internação e responsávelpela manipulação e manutenção do CVCLP-SI de Hickman ${ }^{\circledR}$. Todos os profissionais atenderam ao critério de inclusão definido.

A ação educativa foi realizada em três etapas: primeiro, aplicou-se um questionário composto por dez perguntas com três alternativas de respostas cada das quais apenas uma era correta. As questões abordavam conhecimentos sobre características dos CVCLP, cuidados para a manutenção e a prevenção de oclusão do cateter de Hickman ${ }^{\circledR}$. Após a aplicação do questionário e identificação das lacunas do conhecimento nessa temática, realizou-se aula expositivo-dialogada abordando os temas:

a) definição de permeabilidade de CVC e tipos de oclusão;

b) avaliação e prevenção da oclusão do cateter (verificação da permeabilidade);

c) descrição do cateter de Hickman ${ }^{\circledR}$;

d) técnica de pressão positiva para lavagem e bloqueio do cateter;

e) técnica pulsátil ou start-stop;

f) volume suficiente (em $\mathrm{mL}$ ) de solução salina isotônica 0,9\% para a lavagem dos lúmens após a infusão de medicamentos ou hemocomponentes e coleta de sangue;

g) protocolo de bloqueio do cateter;

h) sequência para o desbloqueio do cateter, conforme protocolo;

i) tópicos importantes sobre a permeabilidade do cateter a serem abordados nos registros de Enfermagem;

j) demonstração da técnica star stop ou pulsátil e técnica de pressão positiva para a lavagem e o bloqueio do cateter.

Essa etapa teve duração média de uma hora e trinta minutos. Os procedimentos foram atualizados de acordo com a literatura existente. Houve 11 aulas distribuídas pelos turnos matutino, vespertino e noturno para atingir toda a equipe de Enfermagem (Quadro 1). Em todas as aulas, as questões levantadas pelos profissionais foram esclarecidas. As aulas foram conduzidas exclusivamente pela pesquisadora principal, enfermeira assistencial do Serviço de Transplante de Medula Óssea há oito anos. O questionário também foi desenvolvido e aplicado pela pesquisadora principal. 
Quadro 1 - Distribuição dos profissionais que participaram das reuniões. Curitiba, PR, Brasil, 2017

\begin{tabular}{ccc}
\hline Data & Período & Número de Participantes \\
\hline \multirow{2}{*}{$10 / 01 / 2017$} & Manhã & 04 \\
& Tarde & 08 \\
& Noite & 04 \\
\hline $12 / 01 / 2017$ & Noite & 02 \\
\hline \multirow{2}{*}{$13 / 01 / 2017$} & Tarde & 05 \\
& Noite & 03 \\
\hline \multirow{2}{*}{$18 / 01 / 2017$} & Manhã & 08 \\
\hline $29 / 01 / 2017$ & Noite & 04 \\
\hline $31 / 01 / 2017$ & Noite & 02 \\
\hline $08 / 03 / 2017$ & Manhã & 03 \\
\hline
\end{tabular}

Imediatamente após finalizar a realização da atividade educativa, o questionário foi reaplicado com vistas a avaliar o aprendizado após as orientações sobre o tema. Os dados coletados foram digitados, organizados em tabelas e as respostas quantificadas foram posteriormente analisadas com o auxílio do programa Microsoft Exce ${ }^{\circledR}$. Para a análise, utilizou-se estatística descritiva mediante frequência absoluta e porcentagem.

A pesquisa foi aprovada pelo Comitê de Ética em Pesquisa com seres humanos da instituição onde foi realizada sob o parecer 1.967.302.

\section{RESUlTADOS}

Do total de 48 colaboradores, dois não preencheram o questionário pré e pós-capacitação e dois não responderam ao questionário pós-capacitação. Desse modo, a amostra final foi composta de 44 participantes que responderam ao questionário em ambos os momentos.

A idade média dos participantes foi de 40,09 \pm 10,31 anos. Demais informações sobre sexo, formação acadêmica e experiência profissional são apresentadas na tabela 1.

Tabela 1 - Caracterização dos participantes quanto ao sexo, formação acadêmica e experiência profissional $(n=44)$. Curitiba, PR, Brasil, 2017. (continua)

\begin{tabular}{|c|c|c|}
\hline Variável & $\mathbf{n}$ & $\%$ \\
\hline \multicolumn{3}{|l|}{ Sexo } \\
\hline Feminino & 41 & 93,18 \\
\hline Masculino & 3 & 6,82 \\
\hline \multicolumn{3}{|l|}{ Graduação } \\
\hline Sim & 41 & 93,18 \\
\hline Não & 2 & 4,55 \\
\hline Cursando & 1 & 2,27 \\
\hline \multicolumn{3}{|c|}{ Faculdade $(n=41)$} \\
\hline Pública & 24 & 58,54 \\
\hline Privada & 17 & 41,46 \\
\hline \multicolumn{3}{|c|}{ Tempo de formação $(n=41)$} \\
\hline $0 \geq 5$ anos & 1 & 2,44 \\
\hline $5 \geq 10$ anos & 19 & 46,34 \\
\hline $10 \geq 15$ anos & 7 & 17,07 \\
\hline $15 \geq 20$ anos & 6 & 14,63 \\
\hline $20 \geq 25$ anos & 0 & 0 \\
\hline $25 \geq 30$ anos & 4 & 9,76 \\
\hline$>30$ anos & 4 & 9,76 \\
\hline
\end{tabular}




\begin{tabular}{|c|c|c|}
\hline \multicolumn{3}{|l|}{ Possui especialização } \\
\hline Sim & 33 & 75 \\
\hline Não & 11 & 25 \\
\hline \multicolumn{3}{|l|}{ Área da especialização $(n=33)$} \\
\hline Auditoria e gestão em saúde & 6 & 18,18 \\
\hline Saúde do trabalhador & 5 & 15,15 \\
\hline Cuidados intensivos & 4 & 12,12 \\
\hline Cuidados intensivos pediátrico e neonatal & 2 & 6,06 \\
\hline Enfermagem médico-cirúrgica & 2 & 6,06 \\
\hline Hematologia e oncologia & 2 & 6,06 \\
\hline Saúde coletiva/pública & 2 & 6,06 \\
\hline Saúde da família & 2 & 6,06 \\
\hline Saúde da mulher/obstetrícia & 2 & 6,06 \\
\hline Informática em saúde & 1 & 3,03 \\
\hline Saúde mental & 1 & 3,03 \\
\hline Pediatria & 1 & 3,03 \\
\hline Geriatria & 1 & 3,03 \\
\hline Urgência e emergência & 1 & 3,03 \\
\hline Docência & 1 & 3,03 \\
\hline \multicolumn{3}{|l|}{ Possui mestrado } \\
\hline Sim & 6 & 13,64 \\
\hline Não & 30 & 68,18 \\
\hline Cursando & 8 & 18,18 \\
\hline \multicolumn{3}{|l|}{ Tempo de experiência na área hospitalar } \\
\hline $0 \geq 5$ anos & 8 & 18,18 \\
\hline $5 \geq 10$ anos & 13 & 29,55 \\
\hline $10 \geq 15$ anos & 9 & 20,45 \\
\hline $15 \geq 20$ anos & 4 & 9,09 \\
\hline $20 \geq 25$ anos & 3 & 6,82 \\
\hline $25 \geq 30$ anos & 4 & 9,09 \\
\hline$>30$ anos & 3 & 6,82 \\
\hline \multicolumn{3}{|l|}{ Tempo de atuação no STMO* } \\
\hline$<1$ ano & 5 & 11,36 \\
\hline$>1$ ano a 5 anos & 23 & 52,27 \\
\hline$>5$ anos a 10 anos & 5 & 11,36 \\
\hline$>15$ anos a 20 anos & 2 & 4,54 \\
\hline$>20$ anos a 25 anos & 4 & 9,09 \\
\hline$>25$ anos & 5 & 11,36 \\
\hline \multicolumn{3}{|l|}{ Lotado no serviço como } \\
\hline Enfermeiro & 35 & 79,55 \\
\hline Técnico em Enfermagem & 7 & 15,91 \\
\hline Auxiliar de Enfermagem & 2 & 4,55 \\
\hline \multicolumn{3}{|l|}{ Turno de trabalho } \\
\hline Matutino & 15 & 34,09 \\
\hline Vespertino & 13 & 29,55 \\
\hline Noturno & 16 & 36,36 \\
\hline
\end{tabular}

*Serviço de Transplante de Medula Óssea

As respostas dos participantes para as questões de um a dez, no período pré e pós-ação educativa, estão apresentadas na tabela 2. 
Tabela 2 - Proporção de respostas corretas ao questionário no período pré e pós-capacitação $(\mathrm{n}=44)$. Curitiba, PR, Brasil, 2017

\begin{tabular}{|c|c|c|c|c|}
\hline \multirow[b]{2}{*}{ Tema da pergunta } & \multicolumn{2}{|c|}{ Pré-capacitação } & \multicolumn{2}{|c|}{ Pós-capacitação } \\
\hline & $\mathbf{n}$ & $\%$ & $n$ & $\%$ \\
\hline \multicolumn{5}{|c|}{ 1. CVC* de curta permanência } \\
\hline Resposta correta & 35 & 79,55 & 41 & 93,18 \\
\hline Resposta incorreta & 9 & 20,45 & 3 & 6,82 \\
\hline \multicolumn{5}{|c|}{ 2. CVC* de longa permanência } \\
\hline Resposta correta & 41 & 93,18 & 42 & 95,45 \\
\hline Resposta incorreta & 3 & 6,82 & 2 & 4,55 \\
\hline \multicolumn{5}{|c|}{ 3. Cateter de Hickman (material e posição) } \\
\hline Resposta correta & 33 & 75 & 39 & 88,64 \\
\hline Resposta incorreta & 11 & 25 & 5 & 11,36 \\
\hline \multicolumn{5}{|c|}{ 4. Cateter de Hickman (características) } \\
\hline Resposta correta & 24 & 54,55 & 29 & 65,91 \\
\hline Resposta incorreta & 20 & 45,45 & 15 & 34,09 \\
\hline \multicolumn{5}{|c|}{ 5. Permeabilidade do cateter } \\
\hline Resposta correta & 41 & 93,18 & 41 & 93,18 \\
\hline Resposta incorreta & 3 & 6,82 & 3 & 6,82 \\
\hline \multicolumn{5}{|l|}{ 6. Oclusão } \\
\hline Resposta correta & 36 & 81,82 & 36 & 81,82 \\
\hline Resposta incorreta & 8 & 18,18 & 8 & 18,18 \\
\hline \multicolumn{5}{|c|}{ 7. Cuidados com o cateter após a inserção } \\
\hline Resposta correta & 1 & 2,27 & 8 & 18,18 \\
\hline Resposta incorreta & 43 & 97,73 & 36 & 81,82 \\
\hline \multicolumn{5}{|c|}{$\begin{array}{l}\text { 8. Lavagem, pressão positiva, refluxo induzido pela seringa e bloqueio } \\
\text { Resposta correta }\end{array}$} \\
\hline \multirow{2}{*}{ Resposta incorreta } & 32 & 72,73 & 43 & 97,73 \\
\hline & 12 & 27,27 & 1 & 2,27 \\
\hline \multicolumn{5}{|l|}{ 9. Bloqueio do cateter } \\
\hline Resposta correta & 37 & 84,09 & 43 & 97,73 \\
\hline Resposta incorreta & 7 & 15,91 & 1 & 2,27 \\
\hline \multicolumn{5}{|c|}{ 10. Volume do priming do cateter (lavagem e bloqueio) } \\
\hline \multicolumn{5}{|c|}{ Resposta correta } \\
\hline \multirow[t]{2}{*}{ Resposta incorreta } & 10 & 22,73 & 24 & 54,55 \\
\hline & 34 & 77,27 & 20 & 45,45 \\
\hline
\end{tabular}

* Cateter Venoso Central; Priming - Volume interno do lúmen.

\section{DISCUSSÃO}

Ao final da ação educativa, os participantes compreendem que o cateter venoso deve ser selecionado de acordo com as necessidades do pacientecomo a condição da rede venosa, o regime e o tempo de tratamento, além do domínio técnico da equipe que manipula o dispositivo ${ }^{(12)}$.

Foi possível fixar o conhecimento de que o cateter venoso central (CVC) é todo cateter cuja ponta fica posicionada em um vaso central, ou seja, veia cava superior ou veia cava inferior ${ }^{(16)}$. Os CVC são divididos em de curta e longa permanência, sendo os CVCLP indicados para pacientes com necessidade de tratamento por tempo superior a 21 dias $^{(12,17)}$. O cateter de Hickman ${ }^{\circledR}$ é um CVCLP semi-implantado (SI) ou tunelizado, instalado cirurgicamente, e pode permanecer por um a dois anos ${ }^{(3)}$.

Os participantes tiveram a oportunidade de discutir sobre o processo de confecção do CVCLP-SI de Hickman $^{\circledR}$ no qual utiliza-se silicone radiopaco hemocompatível e biocompatível ${ }^{(4)}$. O silicone é um material "com estabilidade térmica, química e enzimática, porém oferece baixa resistência à pressão. É resistente, flexível e apresenta estabilidade maior a longo prazo" $\left(17,{ }^{p .76)}\right.$. Esse cateter possui um cuff para a sua fixação no subcutâneo e, em cada lúmen, há adaptador fêmea de bloqueio luer $(\mathrm{s})^{(18)}$. 
O CVCLP-SI de Hickman ${ }^{\circledR}$ confiável é pré-requisito fundamental para os cuidados a pacientes clinicamente graves, como os submetidos ao TCTH, pois viabiliza administrar fluidos intravenosos, medicamentos, hemocomponentes e hemoderivados, nutrição parenteral e monitorar o estado hemodinâmico ${ }^{(11)}$.

Quanto à sua localização, reafirmou-se que a ponta do cateter deve ficar localizada no terço inferior da veia cava superior, próxima à junção cavoatrial (Figura 1), ou na cava inferior acima do nível do diafragma para a inserção femoral ${ }^{(4,7,12,16)}$.

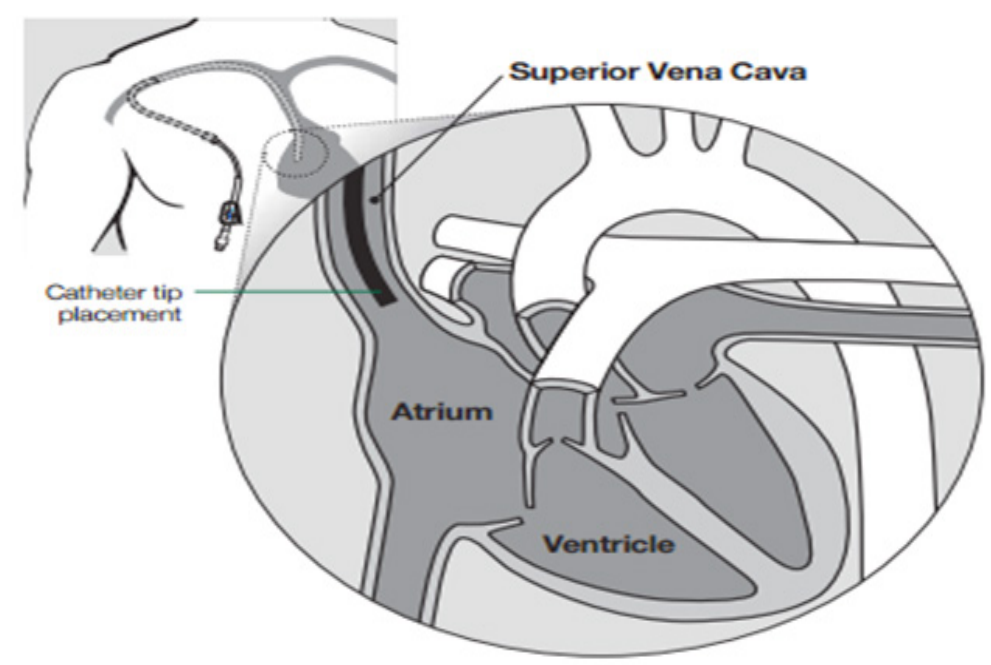

Figura 1 - Posição da ponta do cateter em veia cava superior. Temnpe, AZ, USA, 2016

Sobre as características do cateter de Hickman®, os participantes compreenderam que o calibre do cateter é denominado frenchsizee varia entre sete e 12,5F. Já o total lengthé o tamanho original do cateter (comprimento total), o qual é medido no ato da inserção. Discutiu-se, também, que, para manter a ponta do cateter dentro do vaso central, considera-se cerca de quatro centímetros abaixo da fúrcula e a parte excedente do cateter é cortada ${ }^{(10,18)}$.

Quanto à permeabilidade do cateter, não houve alteração das respostas na segunda fase da aplicação do questionário comparada à primeira fase. Mantiveram-se 93,18\% $(n=41)$ de acertos. Os participantes demonstraram considerar que o objetivo da correta lavagem e bloqueio do cateter é manter a permeabilidade do dispositivo durante o tratamento. Reconhecem que a permeabilidade consiste no ato de infundir fluidos e coletar sangue do CVC, sem resistência, porém, pode ser afetada por oclusão de origem química, física ou trombótica ${ }^{(16)}$.

Oclusão é definida como a incapacidade de infundir solução no lúmen de um cateter, a incapacidade de aspirar sangue do cateter, ou ambos ${ }^{(12)}$, que foi categorizada em três graus de oclusão da seguinte forma: parcial, sem refluxo e completa ${ }^{(16)}$.

Oclusão parcial é definida como a resistência para realizar lavagem ou refluxo lento no CVC; oclusão sem refluxo - não há refluxo de sangue do cateter, porém, a infusão é sem resistência e oclusão completa é definida como a impossibilidade de infusão e aspiração no cateter ${ }^{(16)}$.

Em relação às causas de oclusões do CVC, estas podem ter origem mecânica, química ou trombótica. Mecânica está relacionada com problemas internos ou externos do cateter. Química tem relação com a medicação ou fármaco precipitado. Já a trombótica se caracteriza pela formação de trombo no interior ou em torno do CVC. Orienta-se, ainda, que, na impossibilidade de se determinar o tipo de oclusão, esta deve ser conduzida como trombótica. Há quatro subdivisões de oclusão trombótica: intraluminal, cauda de fibrina, bainha de fibrina e mural ${ }^{(16)}$.

O contato entre soluções incompatíveis resulta em oclusão química. As oclusões trombóticas derivam de depósito de fibrina no lúmen do cateter ou em um vaso circundante. Ambas podem ser evitadas se realizadas as técnicas de lavagem e bloqueio corretas ${ }^{(17)}$. Pesquisadores corroboram tal afirmação quando declaram que obstruções, ou trombos, resultam de falhas na manutenção do cateter ${ }^{(3,5)}$. 
Ainda, resíduo de fibrina dentro do lúmen do cateter, além de progredir para a oclusão do cateter, favorece o risco de infecções por Sthaphylococcus coagulase-negativo ${ }^{(19)}$.

Entre os cuidados com o cateter imediatamente após a inserção, afirmou-se que a avaliação radiográfica deve ser a primeira providência a ser tomada. Somente após a liberação com base na análise da imagem é que se deve realizar o teste de refluxo e fluxo e iniciar qualquer tipo de infusão(20). Diante dessa afirmação, os participantes compreenderam a necessidade de cumprir essa sequência no procedimento para a avaliação da permeabilidade do cateter e para garantir segurança à sua utilização.

No decorrer das discussões, durante as aulas, percebeu-se a necessidade de se criar um indicador de qualidade referente à primeira avaliação após a inserção do cateter vindo ao encontro de uma prática já vigente no serviço que notifica seus eventos. Foram 28 apontamentos corretos, após a ação educativa, para esta questão: “c) cateteres que, após inseridos e no primeiro teste, apresentarem algum tipo de dificuldade de permeabilidade (refluxo ou fluxo) devem ser notificados.

No que se refere à lavagem, à pressão positiva e ao refluxo induzido pela seringa, houve um aumento no número de acertos de $25 \%$ após a ação educativa. Dessa forma, afirmou-se que, para assegurar a permeabilidade do cateter, deve-se realizar a técnica correta de lavagem e bloqueio do dispositivo. A lavagem, ato de mover fluidos para dentro do lúmen do cateter, tem, como finalidade, a retirada de fibrina e medicamentos residuais. A técnica correta para a lavagem é denominada pulsátil ou start-stop, que consiste em infundir pausadamente a solução de lavagem. Essa técnica causa uma turbulência dentro do lúmen do cateter gerando uma limpeza efetiva e deve ser realizada entre as infusões e previamente ao bloqueio do cateter ${ }^{(12)}$.

A lavagem deve ser realizada com solução salina isotônica 0,9\% (SSI), exceto quando se administram medicações incompatíveis com essa solução. Nesses casos, deve-se realizar a lavagem do lúmen com solução glicosada 5\% (SG 5\%) e, então, lavar com SSI previamente ao bloqueio da via. Para a lavagem do lúmen, utiliza-se seringa de $10 \mathrm{~mL}$ ou maior, pois seringas menores geram mais pressão em relação às maiores. Não se deve realizar pressão de infusão superior a 25 psi (172 kPa) sob o risco de danos de vasos sanguíneos ${ }^{(7)}$.

No CVCLP-SI de Hickman ${ }^{\circledR}$, deve-se utilizar SSI para a lavagem fechando o clamp antes de retirar a mão do êmbolo da seringa. Ao injetar a solução de bloqueio, deve-se manter uma pequena quantidade de solução na seringa (tradicional), entre $0,5 \mathrm{e} 1 \mathrm{~mL}$, fechando o clamp antes de retirar a mão do êmbolo da seringa e evitando, assim, o retorno do sangue no lúmen do cateter ${ }^{(12)}$.

No que diz respeito ao bloqueio do cateter, este tem, como definição, o preenchimento do lúmen do cateter, quando este não estiver sendo utilizado, com o objetivo de manter a funcionalidade e a redução do risco de infecção até a próxima utilização. Deve ser precedido de lavagem com SSI ${ }^{(12)}$.

As soluções de bloqueio mais comuns são SSI e solução de heparina ${ }^{(21)}$. Para a prática do bloqueio do CVCLP-SI de Hickman ${ }^{\circledR}$, destacou-seque o diâmetro interno dos lúmens desse cateter é diferente entre si e que é possível calcular o volume exato para cada via, o que oferece mais segurança para essa prática.

A respeito do volume do priming do cateter, lavagem e bloqueio, houve aumento de $31,82 \%$ no número de acertos. Considerou-se que o valor exato do priming depende do valor real do cateter inserido no paciente. Deve-se desconsiderar a parte excedente que foi cortada do cateter. Para a prática do bloqueio do CVCLP-SI, ou seja, o volume adequado para o preenchimento do priming do cateter deve-se levar em consideração o french do cateter, o calibre da via e a porção cortada do cateter após a inserção. Após considerar esses três requisitos, é possível determinar o volume exato de solução de bloqueio necessária ${ }^{(10)}$. Então, soma-se a este valor mais $20 \%$ devido à maior densidade do sangue em relação à das soluções de bloqueio ${ }^{(12)}$.

A ação educativa no trabalho consiste em desenvolver e/ou aprimorar conhecimentos, habilidades e atitudes que objetivam a qualificação profissional e a melhora no processo de trabalho ${ }^{(22)}$. Habilitar a equipe de Enfermagem para o manejo do CVCLP-SI de Hickman ${ }^{\circledR}$, com o objetivo de evitar a oclusão deste dispositivo em pacientes submetidos ao TCTH, é fundamental para garantir a segurança e a melhoria no processo de cuidado de Enfermagem e contribuir para o melhor desenvolvimento do ensaio clínico proposto. 
De acordo com os resultados deste estudo, houve maior número de acertos após a ação educativa, o que demonstra que a apropriação do saber técnico-científicoproposto deverá repercutir na qualidade da assistência prestada ao CVCLP-SI de Hickman ${ }^{\circledR}$.

Como limitação do estudo, aponta-se o fato de as ações educativas terem sido ministradas durante o horário de trabalho dos participantes, o que, possivelmente, causou apreensão devido à necessidade de se ausentar por instantes para o atendimento aos pacientes.

\section{- CONCLUSÃO}

Manter a permeabilidade do CVCLP-SI de Hickman ${ }^{\circledR}$, durante todo o processo do TCTH, é uma tarefa crucial para o sucesso dessa modalidade terapêutica. Após a inserção, realizada em ambiente cirúrgico, a função de mantê-lo funcional é de responsabilidade exclusiva da equipe de Enfermagem que assiste o paciente. Para isso, há a necessidade de especializar-se buscando a melhor prática e assegurando, assim, a segurança e o tratamento adequados.

Os resultados desta pesquisa demonstram que a ação educativa desenvolvida instrumentalizou a equipe de Enfermagem para uma prática mais homogênea no manejo e manutenção da permeabilidade do cateter de Hickman ${ }^{\circledR}$. Durante o desenvolvimento desta pesquisa, suscitou-se a necessidade de se confeccionar um protocolo sobre procedimentos seguros de Enfermagem imediatos à inserção do cateter. Gerou-se, ainda, junto com os participantes, um indicador de qualidade para o serviço, que é a notificação obrigatória de qualquer anormalidade identificada na primeira avaliação do cateter após a sua inserção.

\section{- REFERÊNCIAS}

1. Tormey CA, Snyder EL. Hematopoietic progenitor cell administration. In: Wingard JR, Gastineau DA, Leather HL, Snyder EL, Szczepiorkowski ZM. Hematopoietic stem cell transplantation: a handbook for clinicians. Bethesda: American Association of Blood Banks; 2015. p. 191-199.

2. Timuragaoglu A. The role of the nurses and technicians for stem cell mobilization and collection. Transfus Apher Sci. [Internet] 2015;53(1) [acesso em 24 jul 2017]. Disponível: http://dx.doi.org/10.1016/j.transci.2015.05.012.

3. Bonassa EMA, Bonfim E, Bonfim G, Meira AOS. Administração dos agentes antineoplásicos. In: Bonassa EMA, Gato MIR. Terapêutica oncológica para enfermeiros e farmacêuticos. São Paulo: Atheneu; 2012. p. 263-282.

4. Infusion Nurses Society (INS) Brasil. Diretrizes práticas para a terapia infusional. São Paulo: INS Brasil; 2013.

5. Albuquerque MP. Cirurgia dos cateteres de longa permanência (CLP) nos centros de transplante de medula óssea. Medicina (Ribeirão Preto). [Internet] 2005;38(2) [acesso em 25 jul 2016]. Disponível: http://dx.doi.org/10.11606/issn.21767262.v38i2p125-142.

6. Oliveira RG. Blackbook enfermagem. Belo Horizonte: Blackbook; 2016.

7. Bard Peripheral Vascular (BPV). Nursing procedure manual. [Internet] 2016 [acesso em 19 jun 2016]. Disponível: http://www.bardpv.com/wp-content/uploads/2016/05/BPV-CVCA-1115-0002v-1.1-Hickman-Leonard-Broviac-Nursing-Procedure-Manual.pdf.

8. Baskin JL, Pui C-H, Reiss U, Wilimas JA, Metzger ML, Ribeiro RC, et al. Management of occlusion and thrombosis associated with long-term indwelling central venous catheters. The Lancet. [Internet] 2009;374(9684) [acesso em 05 dez 2016]. Disponível: http://dx.doi.org/10.1016/S0140-6736(09)60220-8.

9. Bard Peripheral Vascular (BPV). Complete line of all-purpose CVCs. [Internet] 2015 [acesso em 19 jun 2016]. Disponível: $\quad$ https://www.crbard.com/CRBard/media/ProductAssets/BardPeripheralVascularlnc/PF10023/en-US/mmqp0b75r5ostiven2lui6j93ti03vwj.pdf. 
10. Bard Peripheral Vascular (BPV). Priming volumes. [Internet] 2015 [acesso em 16 set 2016]. Disponível: http:// www.bardpv.com/wp-content/uploads/2016/04/BPV-CVCA-0216-0010v2.0-2-Hickman-Leonard-Broviac-PrimingVolume-Onesheet.pdf.

11. Ortega ETT, Stelmatchuk AM, Cristoff C. Assistência de enfermagem no transplante de células-tronco hematopoéticas. In: Voltarelli JC, Pasquini R, Ortega ETT. Transplante de células-tronco hematopoéticas. São Paulo: Atheneu; 2009. p. 1031-1098.

12. Infusion Nurses Society (INS). Infusion Nursing Standards of Practice. Journal of Infusion Nursing. [Internet] 2016;39(1) [acesso em 06 jun 2018]. Disponível: http://source.yiboshi.com/20170417/1492425631944540325.pdf.

13. Ministério da Saúde. Portaria n. 198/GM, de 13 de fevereiro de 2004. Institui a política nacional de educação permanente em saúde como estratégia do sistema único de saúde (SUS) para a formação e o desenvolvimento de trabalhadores para o setor e dá outras providências. Diário da União, 13 jan 2004.

14. Ministério da Saúde (BR). Secretaria de Gestão do Trabalho e da Educação na Saúde. Departamento de Gestão da Educação em Saúde. Política Nacional de Educação Permanente em Saúde. [Internet] Brasília: Ministério da Saúde; 2009 [acesso em 19 jun 2016]. Disponível: http://portal.anvisa.gov.br/documents/33856/396770/Pol\%C3\%ADtica+Nacional+de+Educa\%C3\%A7\%C3\%A3o+Permanente+em+Sa\%C3\%BAde/c92db117-e170-45e7-9984-8a7cdb111 faa.

1. 15. de Oliveira AM, Danski MTR, Pedrolo E. Inovação tecnológica para punção venosa periférica: capacitação para uso da ultrassonografia. Rev. Bras. Enferm. [Internet] 2016;69(6) [acesso em 23 jul 2017]. Disponível: http://dx.doi. org/10.1590/0034-7167-2016-0125.

16. Ministério da Saúde (BR). Conselho Nacional de Saúde. Diretrizes e normas regulamentadoras de pesquisa envolvendo seres humanos. Resolução n. 466, de 12 de dezembro de 2012. Brasília; 2012.

17. Canadian Vascular Access Association (CVAA). Occlusion management guideline for central venous access devices (CVADs). Vascular Access. [Internet] 2013;7 (Suppl 1) [acesso em 15 jul 2016]. Disponível: http://www.improvepicc. com/uploads/5/6/5/0/56503399/omg_2013_final_revised.pdf.

18. Agência Nacional de Vigilância Sanitária (ANVISA). Medidas de Prevenção de Infecção Relacionada à Assistência à Saúde. Série Segurança do Paciente e Qualidade em Serviços de Saúde. Brasília: Anvisa, 2017.

19. BardPeripheral Vascular (BPV). Hickman/Broviac/Leonard Central Venous Catheters. [Internet] 2016 [acesso em 11 dez 2016]. Disponível: http://www.bardpv.com/portfolio/hickman-central-venous-catheter/.

20. van Rooden CJ, Schippers EF, Guiot HFL, Barge RM,Hovens MM, van der Meer, FJM et al. Prevention of coagulase-negative staphylococcal central venous catheter-related infection using urokinase rinses: a randomized double-blind controlled trial in patients with hematologic malignancies. J ClinOncol. [Internet] 2008;26(3) [acesso em 28 dez 2016]. Disponível: http://ascopubs.org/doi/pdf/10.1200/JCO.2007.11.7754.

21. European Group for Blood and Marrow Transplantation-Nurses Group (EBMT). Overview of Autologous Haematopoietic Stem Cell Transplantation. In:AertsE, Babic A, Devine H, Kerache F, Mank A, Schouten H, et al. Haematopoietic Stem Cell Mobilisation and Apheresis: A Practical Guide for Nurses and Other Allied Health Care Professionals. [Internet] 2014 [acesso em 24 jul 2017]. Disponível: http://www.iwmf.com/sites/default/files/docs/documents/autologous_stem_cell_collection.pd

22. Calatroia JR. Manutenção da permeabilização de acessos vasculares. In: Martin LGR, Segre CAM. Manual básico de acessos vasculares. São Paulo: Atheneu; 2010. p. 51-58.

23. Costa DB, Vannuchi MTO, Haddad MCFL, Cardoso MGP, Silva LG, Garcia SD. Custo de educação continuada para equipe de enfermagem de um hospital universitário público. Rev. Eletr. Enf. [Internet] 2012;14(2) [acesso em 31 jul 2017]. Disponível: http://dx.doi.org/10.5216/ree.v14i2.14540. 